\title{
Meta-Analysis of the Use of Augmented Reality Applications in Science Teaching
}

\author{
Zeynel Abidin Yilmaz ${ }^{1}$, Veli Batdi²* \\ ${ }^{1}$ Department of Mathematics and Science Education, Faculty of Muallim Rıfat, Kilis 7 Aralık University, Turkey \\ ${ }^{2}$ Faculty of Education, Gaziantep University, Turkey \\ *Corresponding author: veb 27@,hotmail.com
}

\begin{abstract}
This study aims to reach the meta-analysis data by analyzing the augmented reality (AR) applications used in Science Education. The search was conducted on specific databases considering the studies carried out between 2000 and 2019 years. While collecting data, inclusion criteria were considered. After searching the related databases, 24 studies were reached. Based on the random-effects model, the study results revealed that the ES value was $g=0.602$, which means a medium size in the meta-analysis process according to Thalheimer and Cook's (2002) calculation level. Furthermore, z-test calculations conducted to reveal the statistical significance were found to be $z=4.989$, which showed that AR applications had a significant effect on science learning. In this context, it is thought that this technological design, which offers a positive contribution to science education, allows interacting with animations or simulations simultaneously without breaking away from the real world and will serve as a model for future studies.
\end{abstract}

Keywords Applications in Subject Areas, Augmented reality, Improving Classroom Teaching, Meta-analysis, Science

\section{INTRODUCTION}

There has been a tremendous increase in technological developments in recent years. Depending on these developments, new methods are employed in educational environments. Therefore, there are several applications that attract students' attention, trigger their curiosity, and make learning enjoyable and long-lasting. One of these applications is the Augmented Reality (AR) application we have encountered in many fields in our daily life recently. One of the biggest reasons for students' failures in especially Sciences courses is that the abstracts terms are materialized. It is understood from the studies conducted in this regard that the new technologies which have been developed in educational environments have a significant role in overcoming these difficulties and enable students to understand the issues in Science course and influence their attitudes positively. One of these technologies is AR applications which have entered our lives lately. The term AR first appeared in our lives in 1990, together with the ongoing technological developments, and reached a significant mass thanks to the preparation of flash-based AR applications in 2008 (Johnson, Levine, Smith, \& Stone, 2010).

AR instruments have been used in engineering, advertisement, marketing, architecture, construction, entertainment, health, and military (Azuma, 1997). AR applications have begun to be employed in educational environments depending on the increase of mobile devices (desktop computers, laptops, smartphones, etc.) lately (Billinghurst, 2002; Johnson et al., 2010). AR environments provide several benefits such as cost reductions, directing educational studies, ensuring track plans, facilitating applications, creating cooperative environments, facilitating learning, enabling new learning environments, developing socialization, and supporting the researchoriented learning environments (Abdüsselam and Karal, 2015). It is envisaged that AR in education will be more effective in teaching tiny objects and events that are impossible to be seen with eyes, materialize the abstract concepts, and present sophisticated knowledge (Walczak, Wojciechowski, \& Cellary, 2006). Abdüsselam and Karal (2012) observed in their studies that students have shorter periods of attention in a traditional class environment, and their interests can be easily distracted. On the other hand, in an AR environment, their attention period increases through the highly technological device, materializing the abstract concepts and facilitating comprehension.

Received: 19 December 2020

Revised: 01 April 2021

Published: 05 July 2021 


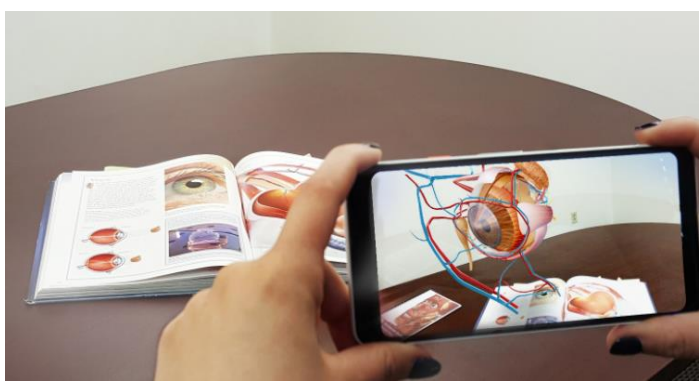

Figure 1 The human anatomy atlas app

(https://www.visiblebody.com/anatomy-and-physiologyapps/human-anatomy-atlas)

The studies indicated that AR technologies increase students' learning levels compared to traditional class environments (Freitas \& Campos, 2008; Kerawalla, Luckin, Seljeflot, \& Woolard, 2006). AR instruction environments constitute profound learning by ensuring the objects appear from different perspectives under challenging subjects by attracting students' interests and attention. Therefore, it is necessary to use AR technologies in science education where students have difficulty understanding subjects. When the related literature is reviewed, it is seen that the use of AR applications in education positively influences the learning process (Kerawalla et al., 2006). Students can have opportunities to see the cases in the modeled shapes in real environments, which they cannot perceive through their sense organs, and their interests and attentions are more attracted thanks to the differences added in the books (Billinghurst, Kato, \& Poupyrev, 2001). Therefore, it is understood that the related material will constitute an effective process and a productive environment.

While the literature was searched, many AR applications were used in almost every field in our daily lives besides education. For instance, there is an application called Touch Surgery which specializes in the surgical simulation used in the health field. It gives users the possibility to launch an AR platform to practice surgeries on virtual patients. In addition, many innovative projects created for medical education and training include Microsoft HoloLens, mixed reality smart glasses. In Figure 1, the HoloAnatomy app is seen, which was developed by Case Western Reserve University and the Cleveland Clinic. This high-level technological app helps medical students learn anatomy. Thus, surgeons do not need to leaf through books or medical journals. As HoloAnatomy App provides them to learn the process of a surgical procedure in an almost real-life scenario, there is no need to go over the books.

It is possible to view the three-dimensional drawings of the structure planned to be built, created with CAD programs, by a device with an augmented reality application (Figure 2). Thus, the designer and the user can have the opportunity to gain experience about some details such as the front view of the building, the material to be

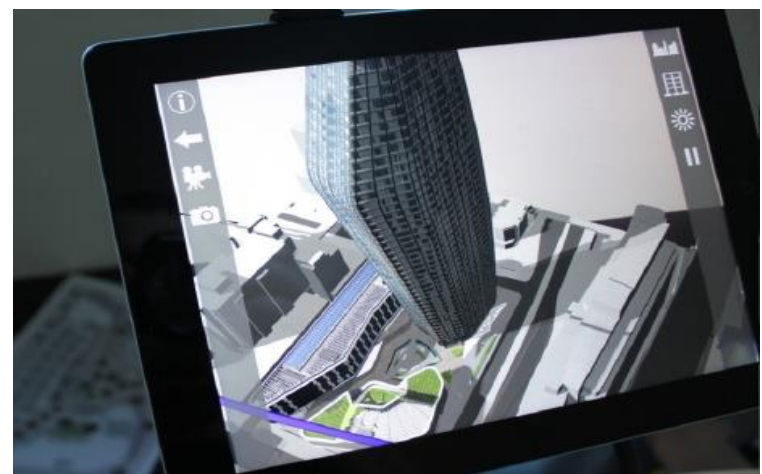

Figure 2 Augmented reality application used in architecture

used, and design feedback in a more realistic way than it appears on the computer screen (Kiliç, 2016). As can be seen, the phenomenon of $\mathrm{AR}$, which has evolved towards mixed reality by blending with virtual reality, provides an opportunity for the transformation and reconstruction of information by changing the perception world of individuals (Anil ve Batd1, 2020). AR applications whose usage area is expanding with technology-based development in mobile vehicles have a general usage area from architecture to medicine, from military applications to museums, from tourism to education.

In the literature, it has been found that some other studies on AR have been carried out. However, it can be stated that these studies are different in purpose and scope from our current research. In detail, some studies examined the features, advantages, and effectiveness of $A R$ in general, rather than examining it through a field or discipline (Chen, Liu, Cheng, Huang, 2017). Some examined through meta-analysis, where they revealed advantages of $\mathrm{AR}$ in terms of educational purposes in general (Bacca, Baldiris, Fabregat, Graf, \& Kinshuk, 2014; Saidin, Halim \& Yahaya, 2015). Another one made a systematic review on the application of the AR regarding both the advantages of AR in the general scope and problems encountered in its application (Akçayır \& Akçayır, 2017).

Furthermore, in a systematic review from a conference paper (Swensen, 2016), the contribution of AR to Science teaching is evaluated in the context of specific topics. As a result of the examination of the studies reached from particular journals determined by the researcher, it was seen that qualitative results were acquired by composing some theme titles that were thought to affect science teaching. However, it can be stated that in the context of metaanalysis, our current study examines the studies carried out on AR applications in the field of science and covers the period between 2000-2017. Thus, different from other studies, it is carried out to reflect the results of AR studies in different periods specific to the Science field. 


\subsection{The Aim of the Research}

This research aims to provide an investigation by conducting a meta-analysis of AG applications. It is known that the use of AR technologies, particularly on the difficult issues both in other fields (Ibanez et al., 2020; Rashevska, Semerikov, Zinonos, Tkachuk, \& Shyshkina, 2020) and in science teaching, will positively influence students' achievements by making learning processes enjoyable. In addition, AR learning environments allow students to see two-dimensional objects in three dimensions and examine these objects from different angles by learning, doing, and living. So, more effective and long-lasting learning occurs (Dunleavy, Dede, \& Mitchell, 2009; Wojciechowski \& Cellary, 2013; Yen, Tsai \& Wu, 2013). On the other hand, the comparative studies conducted concerning AR and traditional class applications revealed that $\mathrm{AR}$ technologies increase the students' learning (Freitas \& Campos, 2008). In this regard, the results of AR applications in science teaching through a meta-analysis based on the document analysis in the literature review were aimed to be included for a detailed review. However, when the AR studies in the literature are examined, it is seen that these studies are generally conducted in one dimension that was whether on education in general (Garzon, Pavon, Baldris, 2019; Garzon \& Acevedo, 2019) or science field but in a qualitative aspect (Swensen, 2016), thus the current research is thought to be different at this point. Therefore, this study is planned to conduct a meta-analysis of studies on AR. In this way, it is expected that a general conclusion can be drawn by seeing what aspects are conducted and what the level of its effect is in the scientific field related to AR. Thus, the main aim of this study is to see "What is the effect size of AR applications on academic success in Science through meta-analytic examinations concerning document analysis?"

\subsection{The Significance of the Research}

Educational practices are at the top of the academic studies that have been improved by using AR technology. These applications can be used as educational materials at all levels, from primary education to university. When looking at the studies conducted within the framework of AR applications in education, they are generally related to the research about examining the effectiveness of $A R$ in the educational context (Garzon, Pavon, Baldris, 2019; Garzon \& Acevedo, 2019). Some of these studies reached some results, including participants' views on AR in science teaching (Timur \& Özdemir, 2018; Durak \& Yllmaz, 2019) or reflected the use and effectiveness of AR applications in Chemistry and biology lessons (Abriata, 2018). However, the reason for this research is that there are not so many studies conducted on the meta-analysis study, including AR applications in the field of science. Therefore, it is thought that the meta-analysis of AR use between 2000 and 2017 in the science field and sharing the results obtained will contribute to the integration of findings and the literature.

\section{METHOD}

\subsection{Research Design}

In this research, the effectiveness of AG technology was determined by employing meta-analysis. For this purpose, the meta-analysis method that can be defined as a statistical analysis method to compound findings of independent studies implemented on a similar subject (Crombie \& Davies, 2009) or as an analysis technique that combines the results of many small individual studies using one or more statistical methods to give more information (Hedges ve Olkin, 1985) was made use of considering the inclusion criteria of the present research.

\subsection{Data Collection And Inclusion Criteria}

In the context of meta-analysis, ScienceDirect, Web of Science, Taylor \& Francis Online, EbscoHost, ProQuest Dissertation \& Theses, Council of Higher Education Dissertation Center, and Google Scholar search engines were scanned the years between 2000 and 2019. Keywords such as "augmented reality in science, science, and augmented reality applications" were used as search terms. A total of 238 studies involving AR applications concerning the post-test scores of academic success were reached. In the context of the inclusion criteria, 26 data were derived from 24 studies. The selection of 24 studies out of 238 ones was made in the context of the inclusion criteria. Inclusion criteria are stated as follows:

- An experimental or quasi-experimental study conducted for the use of AR in the field of science,

- Carried out at many levels from primary school to university,

- Examining the effect of AR on academic achievement in science,

- Written in Turkish or English,

- Including enough data to allow calculation of effect size in meta-analysis [sample size belonging to the experimental and control groups (n), arithmetic average (x), standard deviation (sd)],

- Carried out in the period between 2000-2017.

\subsection{Exclusion Criteria}

In the literature review, the congress studies and the abstracts presented in the abstract booklet regarding AR in science teaching were excluded because they do not contain sufficient data for meta-analysis. Lipsey and Wilson (2001) stated that studies included in a meta-analysis should be related to the research subject and should contain statistical data necessary for analysis. In addition, among the studies obtained through the literature review, those that were not suitable for the scope of the research, included only qualitative findings, and did not comply with the inclusion criteria were excluded from the meta-analysis study. 
Table 1 Homogeneous distribution values in effect models concerning academic success score of the studies included meta-analysis, average effect size, and confidence intervals

\begin{tabular}{lllllllll}
\hline $\begin{array}{l}\text { Model } \\
\text { Type }\end{array}$ & \multirow{n}{*}{ Z } & Z & Q & ES & \multirow{2}{*}{$\mathbf{I}^{2}$} & \multicolumn{2}{c}{ \% 95 Confidence Interval } \\
Lower Limit & Lower Limit \\
\hline FEM & 26 & 11.434 & 0.00 & 170.842 & 0.516 & 86.37 & 0.427 & 0.604 \\
REM & 26 & 4.989 & 0.00 & 24.053 & 0.602 & & 0.366 & 0.839 \\
\hline
\end{tabular}

df:25

\subsection{Analyzing the Data}

A summary table of studies, including the qualities of the studies, was created to use them in the process as it was planned. The codes, names, types, and publication years of the studies, the author names, and the statistical data derived from the experimental and control groups (n, , sd) were displayed in this table. The dependent variable was determined as the effect size concerning the effect of AR on academic success. Comprehensive Meta-Analysis (version 2.0) package program was used in the metaanalysis of the data recorded from the studies included in the study. Effect sizes were interpreted by taking into account Thalheimer and Cook's level classification (2002). In order to ensure the coding reliability of the research, the coding processes were examined separately by at least two independent coders (Card, 2012). In case of any inconsistency, the analysis continued until a definite agreement was reached between the coders by restarting the coding processes. In this way, it was ensured that two different coders examined the data set and worked independently. As a result, the inter-rater reliability was found to be 0.86 according to Cohen's (1960) consistency values.

\subsection{Effect Size and Model Selection}

Meta-analysis requires a representation of scientific studies in terms of effect sizes. Effect size can be expressed as the frequency of existence of a phenomenon in a population (Cohen, 1988) or as a standardized value for different scaling instruments used in every study (Turner \& Bernard, 2006). The use of different effect size indices (Cohen's d, Hedge's g, or Glass's $\Delta$ ) is essential in obtaining standardized values and presenting correct findings and correct interpretation of the study. In the present study, Hedges' g effect size index, which gives the pooled and standardized means difference between groups, was used (Hedges, 1981).

In determining the effect sizes during meta-analytical processes, analyzes are made according to the fixed effects model (FEM) and random effects (REM) model. There are observed effect size and real effect size concepts in model selection. Schmidt, Oh, and Hayes (2009) stated that the conditions under which FEM would be suitable are minimal. Therefore, many researchers recommend using REM instead of FEM for meta-analysis studies (Field, 2003). As studies included in this research showed diversity in terms of study design and variables, thus being heterogeneous, the random effect model was chosen as the most appropriate model (Borenstein, Hedges, Higgins, \& Rothstein, 2010). The effect sizes of all studies included in the current research were presented at the end (Appendix1).

The $\mathrm{I}^{2}$ test, developed as a complement to the homogeneity test in the meta-analysis, reveals a more evident result regarding heterogeneity. Unlike the Q statistics, this value is not affected by the number of studies. While interpreting, 25\% indicates a low level of heterogeneity, $50 \%$ moderate heterogeneity, and 75\% high level of heterogeneity (Cooper et al., 2009). In the present study, the REM was used in selecting the model because the I2 value showed a high level of heterogeneity with 86.37 .

\section{RESULTS}

The section of this study presents meta-analysis results regard to AR. The meta-analysis of all the studies concerning AR in teaching science was conducted herein, and the analysis is displayed in Table 1.

When Table 1 is examined, it was calculated as a result of the analyses conducted according to random effects model that the standard data 0.121 ; the upper limit (0.839) and lower limit (0.366) of $95 \%$ confidence interval with average effect size $g=0.602$. These values indicate that academic success is more effective in favor of $A R$ applications than the traditional approach. When the effect size is considered, this value was accepted to be at a medium level according to the classifications made by Thalheimer and Cook (2002). As a result of z-test calculations, which were conducted to reveal the statistical significance, this value was $z=4.989$. Based on this result $(\mathrm{p}=0.00)$, it can be stated that the analysis is statistically significant. As a result of the homogeneous test, Q statistical value was calculated as 24.053 . The value was 37.652 at a $95 \%$ significance level with 25 degrees of freedom in the X2 table. It was seen that Q statistical value (24.053) did not exceed the chi-squared critical value $(\chi 2(0.95)=24.053)$. The average effect sizes of 26 data included in the meta-analysis according to the effect models are indicated in Table 1. AR applications on academic success were found in the fixed-effect model as $\mathrm{g}$ $=0.516$ and random-effects model as $\mathrm{g}=0.602$, meaning that the applications have a positive effect on academic success. 


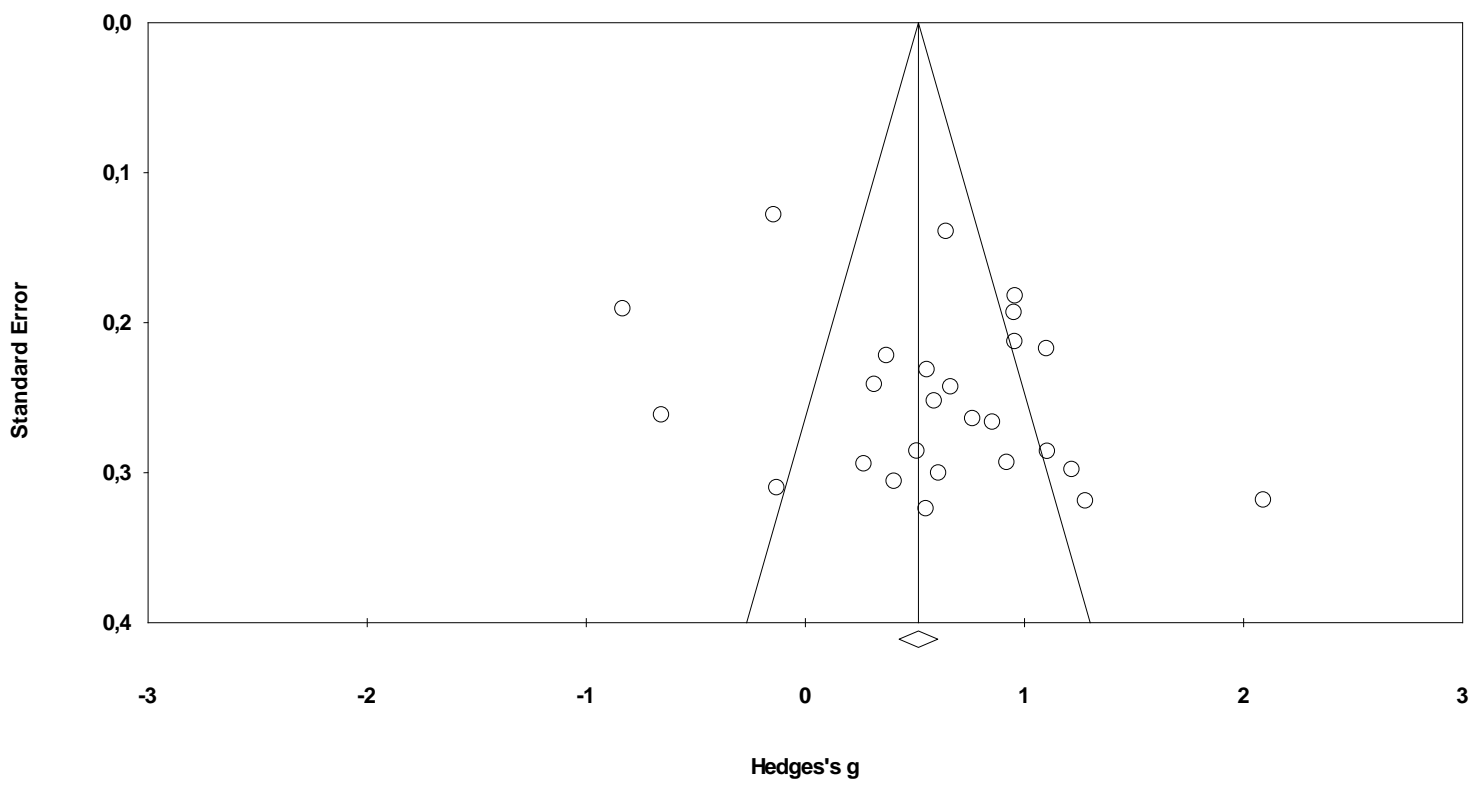

Figure 3 Funnel plot of standard error by Hedge's g

\subsection{Results of Publication Bias}

Publication bias means a tendency for studies with positive and statistical significance to be published compared to studies that are negative and without statistical significance. Publication bias above a certain level affects the average effect size to be calculated and makes it higher than it should be (Borenstein, Hedges, Higgins, \& Rothstein, 2009). The publication bias in the present study was calculated in two ways, one of which is considering Rosenthal's (1979) classic fail-safe number, and the other one is the funnel plot. Figure 1 shows the results of the funnel plot. In the funnel plot chart, the standard error value of the study is seen on the $\mathrm{Y}$-axis while the effect size value on the $\mathrm{X}$-axis. Thus, studies with small standard error values are collected towards the upper part of the funnel chart (Borenstein et al., 2009).

As seen in Figure 3, the effect size of the studies included in this study was symmetrically located on both sides of the vertical line, in the upper and middle regions. Therefore, this position is interpreted as no publication bias (Borenstein et al., 2009). On the other hand, Rosenthal's Classic Fail-Safe N calculation was also checked. Classic Fail-Safe $\mathrm{N}$ specifies the number of studies required to make the effect size "ineffective" by calculating the number of studies that may be missing in a meta-analysis study (Borenstein et al., 2009). Therefore, it can be stated that the effect size value calculated with the current meta-analysis research is 977 (Appendix-2). However, considering the study's inclusion criteria and 24 studies included, this number can be considered as all of the studies that could be reached. Therefore, it can be accepted that there is no publication bias in the current meta-analysis since there is no possibility to reach 977 more studies other than these studies, and this number is very large.

\section{DISCUSSION AND RECOMMENDATION}

In this research, the effect of AR applications on science teaching was aimed to be evaluated with regard to meta-analysis. As a result of scanning the studies concerning AR applications in science teaching, a metaanalysis was conducted to analyze the obtained studies in the research. According to the results of 26 data, the effect of AR applications in the instructional process on academic success was found to be at a medium level. This result overlaps with the ones of several studies conducted in national (Yen, Tsai \& Wu, 2013; Y1lmaz, 2016; Chang, Chung \& Huang, 2016; Yilmaz \& Batd1, 2016) and international arena (Dunleavy et al., 2009; Wojciechowski \& Cellary, 2013; Yen et al., 2013). Similar to the results that showed a positive impact of AR on Science academic success, this new technology was also seen to increase the satisfaction and motivation of students (Fonseca, Martí, Redondo, Navarro, \& Sánchez, 2014). Besides, the fact that the number of studies dealing with AR in teaching atomic models subject in science teaching at the university level is quite a few took attention of the authors. In this way, for future research, in one sense, it can be suggested to conduct research related to this subject in the science field. Moreover, when the levels of subjects were considered, it was seen that fewer studies were conducted at the university level on the related subject of atomic models. Thus, it is suggested to use AR on teaching atomic models to university students. 


\section{CONCLUSION}

In this study, using AR in science teaching on academic achievement was examined through the meta-analysis process. For this purpose, the effect sizes of the studies accessed through the databases searched from the context of the study's inclusion criteria were calculated, and the average effect size of 26 data in 24 studies was found to be at the medium level $(\mathrm{g}=.602)$ and significant. Within the context of meta-analysis in this study, it was figured out from the included studies that while teaching and learning abstract subjects in science, presenting the subjects more concretely and straightforwardly using AR can provide more effective and permanent learning. This result means that AR applications positively affect academic achievement in science teaching. On the other hand, the values obtained from the funnel plot and fail-safe $\mathrm{N}$ calculations conducted for the reliability of the research in the meta-analysis process revealed that there is no publication bias in the study. The fact that the current research consists of only the science field does not mean that AR is only effective in this scope. At this point, ARbased research encountered in literature reviews and studies in the data collection process has shown that AR has an application and effect dimension in many different areas such as health, economy, security, tourism, the industry as well as education.

Especially in the literature review of the study, it has been found that more studies have been conducted on AR recently. This situation may arise from technological developments and changes. In addition, the pandemic process has led the whole world to distance learning, online education, and virtual environments by moving the world away from real learning environments. This orientation has increased the interest and need for technologies that improve and facilitate the effectiveness of the learning process. For instance, it is concluded from the research results that $\mathrm{AR}$ technologies make business and operations in the tourism sector easy and reliable in the pandemic process (Mohanty, Hassan \& Ekis, 2020). Therefore, it is stated in their research that there will be an excellent demand for AR both to ensure tourist safety and to create unique, accessible, personalized, and memorable experiences. In addition, another study resulted that the integration of AR with mobile-based technology increased the value and reach of AR (Michele, Michele \& Fabio, 2013). As this technology is hoped to ensure so many facilities, educational institutions are thought to explore the possibilities of virtual trips as a substitute for real-life trips (Yung \& Khoo-Lattimore, 2019), of the contents of courses in distance education. There is much more to say about the impact of AR on many subjects and its use in many fields. Therefore, future research is highly recommended to carry out different AR effects on different fields and disciplines.

\section{LIMITATIONS AND IMPLICATIONS}

While searching the studies for the meta-analysis process within the current research, specific databases were used. However, it can be stated that researchers can keep their scope wider by using different databases other than this. In addition, the effectiveness of AR applications in different subject areas/ disciplines can be evaluated. For example, Berryman (2012) stated that AR technology covers various subjects, target groups, and academic levels. Moreover, alternative studies can be conducted by making differences in the inclusion criteria for the analysis, such as the research design/type, publication years (period), and moderator variables.

It is remarkable and essential that this research is carried out with AR applications, which can be considered one of the most significant developments in this technology age. Performing a meta-analysis process, which includes combining the current study results in the literature, can generalize the results on the relevant subject. As can be understood from the research results in the literature and the current research results, the effectiveness of AR applications in different dimensions can be evaluated, which can provide permanent and meaningful learning at a reasonable level.

\section{ACKNOWLEDGMENTS}

The present study was not supported by any foundations, institutions, or others. Therefore, there is no funding to report for this submission. We confirm that all co-authors contributed equally to the study. To the best of our knowledge, there is no conflict of interest.

\section{REFERENCES}

(The references marked with an asterisk. (*) are the ones included in the analysis.)

*Abdüsselam, M. S. (2014). Development and evaluation of an instructional material for physic lesson magnetism subject based on augmented reality environment (Unpublished doctoral dissertation). Karadeniz Technical University, Trabzon, Turkey.

Abdüsselam, M. S., \& Karal, H. (2012). The effect of mixed reality environments on the students' academic achievement in physics education: 11th grade magnetism topic example. Journal of Research in Education and Teaching, 1(4), 170-181.

Abdüsselam, M. S., \& Karal, H. (2015). Artırılmış gerçeklik [Augmented Reality]. In B. Akkoyunlu, A. İşman, H. F. Odabaşı (Eds.), Eŭgitim Teknolojileri Okumalar [Educational Technology Readings], 2015 (pp. 149-171). Ankara: TOJET. ISBN: 978- 605- 318- 126- 2.

Abriata, L. A. (2018). Towards commodity, web-based augmented reality applications for research and education in chemistry and structural biology. arXiv preprint arXiv:1806.08332.

Akçayır, M. \& Akçayır, G. (2017). Advantages and challenges associated with augmented reality for education: A systematic review of the literature. Educational Research Review, 20, 1-11.

*Akçayır, M., Akçayır, G., Pektaş, H. M, \& Ocak, M. A. (2016). Augmented reality in science laboratories: The effects of augmented reality on university students' laboratory skills and attitudes toward science laboratories. Computers in Human Behavior, 57, 334-342.

*Aktamış, H. \& Arıc1, V. A. (2013). The effects of using virtual reality software in teaching astronomy subjects on academic achievement 
and retention. Mersin University Journal of the Faculty of Education, 9(2), 58-70.

*Altıntaş, G. (2018) . The effect of augmented reality applications on teacher candidates' scientific epistemological beliefs and musconceptoons: global warming (Unpublished doctoral dissertation). Mehmet Akif Ersoy University, Burdur, Turkey.

Anıl, Ö \& Batdı, V. (2020). Artırılmış gerçeklik: eğitimdeki uygulamalar üzerine kuramsal bir çalışma [Augmented reality: a theoretical study on applications in education]. In Paksoy, S. (Ed.). Sosyal Bilimlerde Örgün Calısmalar-1 [Original Studies in Social Sciences-1]. Ankara: Iksad Publications.

Azuma, R. (1997). A survey of virtual reality. Presence: Teleoperators and Virtual Environments, 6(4), 355-385.

*Babur, A. (2016). The Effects Of Using Of Augmented Reality, Simulation And Real Object On Learning Achrevements, Motwation And Psychomotor Performance (Unpublished doctoral dissertation). Sakarya University, Sakarya, Turkey.

Bacca, J., Baldiris, S., Fabregat, R., Graf, S., \& Kinshuk. (2014). Augmented Reality Trends in Education: A Systematic Review of Research and Applications. Educational Technology \& Society, 17(4), 133-149.

Berryman, D. R. (2012). Augmented reality: a review. Medical Reference Services Quarterly, 31(2), 212-218. doi: https://doi.org/10.1080/02763869.2012.670604

Billinghurst, M. (2002). Augmented reality in education. New Horizons for Learning, 12(5), 1-5.

Billinghurst, M., Kato, H., \& Poupyrev, I. (2001). The magicbookmoving seamlessly between reality and virtuality. Computer Graphics and Applications, IEEE, 21(3), 6-8.

Borenstein, M., Hedges, L. V., Higgins, J. P. T., \& Rothstein, H. R. (2009). Introduction to meta-analysis (1 ${ }^{\mathrm{st}} \mathrm{ed}$.), UK: John Wiley \& Sons, Ltd.

Borenstein, M., Hedges, L. V., Higgins, J. P. T., \& Rothstein, H. R. (2010). A basic introduction to fixed-effect and random effect models for meta-analysis. Research Synthesis Methods, 1(1), 97-111.

*Buluş Kırıkkaya, E. \& Şentürk, M. (2018). The impact of using augmented reality technology in the solar system and beyond unit on the academic achievement of the students. Kastamonu Education Journal, 26(1), 181-189.

*Cankaya, B. \& Girgin, S. ( 2018). The effect of augmented realty technology on the academic success of science course. Journal of Social And Humanities Sciences Research, 5(30), 4283-4290.

Card, N. A. (2012). Applied meta-analysis for social science research. New York: The Guilford Press.

*Chang, R. C., Chung, L. Y., \& Huang, Y. M. (2016). Developing an interactive augmented reality system as a complement to plant education and comparing its effectiveness with video learning. Interactive Learning Environments, 24(6), 1245-1264. DOI:10.1080/10494820.2014.982131.

Chen P., Liu X., Cheng W., \& Huang R. (2017) A review of using Augmented Reality in Education from 2011 to 2016. In Popescu, E. et al. (Eds.) Innovations in Smart Learning. Lecture Notes in Educational Technology. Springer, Singapore. https://doi.org/10.1007/978-981-10-2419-1 2

*Chiu, J. L., Dejaegher, C. J. \& Chao, J. (2015). The effects of augmented virtual science laboratories on middle school students' understanding of gas properties. Computers \& Education, 85, 59-73.

*Civelek, T., Ucar, E., Ustunel, H., \& Aydın, M. K. (2014). Effects of a haptic augmented simulation on k-12 students' achievement and their attitudes towards Physics. Eurasia Journal of Mathematics, Science \& Technology Education, 10(6), 565-574.

Cohen, J. (1960). Coefficient of agreement for nominal scales. Educational and Psychological Measurement, 20(1), 36-46.

Cohen, J. (1988). Statistical power analysis for the behavioural sciences. New York: Erlbaum.
Cooper, H., Hedges, L. V., \& Valentine, J. C. (Eds.). (2009). The handbook of research synthesis and meta-analysis (2nd edition). New York: Russell Sage Publication.

Crombie, I. K. \& Davies, H. T. (2009). What is meta-analysis. What is series? (2nd ed.). Retrieved April, 15, 2019 from http://www.bandolier.org.uk/painres/download/whatis/MetaAn.pdf

*Demirel, T. (2017). The effect of augmented realty activities supported by argumentation approach on academic achievement, critical thinking skills, motivation towards science and technology course and argumentation skill (Unpublished doctoral dissertation). Çukurova University, Adana, Turkey.

Dunleavy, M., Dede, C., \& Mitchell, R. (2009). Affordances and limitations of immersive participatory augmented reality simulations for teaching and learning. Journal of Science Education and Technology, 18(1), 7-22.

Durak, A., \& Yilmaz, F. G. K. (2019). Artirilmiş gerçekliğin eğitsel uygulamalari üzerine ortaokul öğrencilerinin görüşleri [Opinions of secondary school students on the educational applications of augmented reality]. Abant İzzet Baysal Üniversitesi Eğitim Fakültesi Dergisi, 19(2), 468-481.

*Erbaş, Ç. (2016). The effects of mobile augmented reality applications on students' academic achievement and motivation (Master's Thesis). Süleyman Demirel University, Isparta, Turkey.

*Eroğlu, B. (2018). Evaluation of teaching astronomy concept with augmented reality application for secondary student (Master's thesis). Karadeniz Technical University, Trabzon, Turkey.

Field, A. P. (2003). The problem in using fixed-effects models of metaanalysis on real world data. Understanding Statistics, 2, 77-96.

Fonseca, D., Martí, N., Redondo, E., Navarro, I., \& Sánchez, A. (2014). Relationship between student profile, tool use, participation, and academic performance with the use of Augmented Reality technology for visualized architecture models. Computers in Human Behavior, 31, 434-445.

Freitas, R., \& Campos, P. (2008). SMART: a SysteM of Augmented Reality for Teaching $2^{\text {nd }}$ grade students. In Proceedings of the $22^{\text {nd }}$ British HCI Group Annual Conference on People and Computers: Culture, Creativity, Interaction-Volume 2 (pp. 27-30). British Computer Society.

Garzon, J., \& Acevedo, J. (2019). Meta-analysis of the impact of augmented reality on students' learning gains. Educational Research Review, 27, 244-260.

Garzon, J., Pavon, J., \& Baldiris, S. (2019). Systematic review and metaanalysis of augmented reality in educational settings. Virtual Reality, 23(4), 447-459.

*Golden, S. A. (2016). Augmented $3 d$ bolograms in higher education, increasing students' learning outcome scores: a mixed methods Study (Doctoral dissertation). Retrieved from ProQuest Dissertations and Theses database. (UMI No. 10256536).

Hedges, L. (1981). Distribution theory for Glass's estimator of effect size and related estimates. Journal of Educational Statistics, 6, 107-112.

Hedges, L. V., \& Olkin, I. (1985). Statistical methods for meta-analysis. New York: Academic Press.

*Hsiao, K. F., Chen, N. S. \& Huang, S. Y. (2012). Learning while exercising for science education in augmented reality among adolescents. Interactive Learning Environments, 20(4), 331-349. doi:10.1080/10494820.2010.486682

Ibanez, M. B., Portillo, A. U., Cabada, R. Z., \& Barron, M. L. (2020). Impact of augmented reality technology on academic achievement and motivation of students from public and private Mexican schools. A case study in a middle-school geometry course. Computers \& Education, 145, 103734. https://doi.org/10.1016/i.compedu.2019.103734

*Ibanez, M. B., Serio, A. D., Villaran, D. \& Kloos, C. D. (2014). Experimenting with electromagnetism using augmented reality: Impact on flow student experience and educational effectiveness. Computer \& Education, 71, 1-13. 
Johnson, L., Levine, A., Smith, R., \& Stone, S. (2010). The 2010 Horizon Report. New Media Consortium. 6101 West Courtyard Drive Building One Suite 100, Austin, TX 78730.

Kerawalla, L., Luckin, R., Seljeflot, S., \& Woolard, A. (2006). Making it real: exploring the potential of augmented reality for teaching primary school science. Virtual Reality, 10(3-4), 163-174.

Kılıç, T. (2016). Artırlmıs gerçeklike teknolojisinin ic mekân tasarm sürecinde kullanulmast [The use of augmented reality technology in the interior design process] (Master's Thesis). Mimar Sinan Fine Arts University, Institute of Science, Department of Interior Architecture, Istanbul.

*Küçük, S. (2015). Effects of learning anatomy via mobile angmented reality on medical students' academic achievement, cognitive load, and views toward implementation (Doctoral dissertation). Atatürk University, Erzurum, Turkey.

Lipsey, M. W., \& Wilson, D. B. (2001). Practical meta-analysis. London, New Delhi: Sage.

Michele, G., Michele, D.D. \& Fabio, S. (2013). VisitAR: a mobile application for tourism using AR. SIGGRAPH Asia 2013 Symposium on Mobile Graphics and Interactive Applications, pp. 1-6.

Mohanty, P., Hassan, A., \& Ekis, E. (2020). Augmented reality for relaunching tourism post-COVID-19: socially distant, virtually connected. Worldwide Hospitality and Tourism Themes. 12(6), 753-760.

Rashevska, N. V., Semerikov, S. O., Zinonos, N. O., Tkachuk, V. V., \& Shyshkina, M. P. (2020). Using augmented reality tools in the teaching of two-dimensional plane geometry. CEUR Workshop Proceedings, 2731, 79-90.

Rosenthal, R.(1979). The "file drawer problem" and tolerance for null results. Psychol Bull, 86, 638-41.

*Sahin, D.,(2017). Effect of science teaching with the augmented reality technology on secondary school students' achrevement and their attitude towards the course (Unpublished master's thesis). Atatürk University, Erzurum, Turkey.

Saidin, N. F., Halim, N. D. A., \& Yahaya, N. (2015). A review of research on augmented reality in education: Advantages and applications. International Education Studies, 8(13), 1-8.

*Sar1kaya, M. (2015). Effects of augmented reality applications on students' achievement, misconceptions and course engagement (Doctoral dissertation). Gazi University, Ankara, Turkey.

Schmidt, F. L., Oh, I.-S., \& Hayes, T. L. (2009). Fixed- versus randomeffects models in meta-analysis: model properties and an empirical comparison of differences in results. British Journal of Mathematical and Statistical Psychology, 62, 97-128.

*Sentürk, M. (2018). The investigation with Solomon four-group design on the effect of using mobile angmented reality (AR) applications in the unit titled solar system and beyond in the seventh-grade on the students' academic success, motivation, science and technology attitude (Master's thesis). Kocael University, Kocaeli, Turkey.

Swensen, H. (2016). Potential of augmented reality in sciences education a literature review. A paper form Proceedings of ICERI2016 Conference, 14th-16 th November 2016, Seville, Spain.

Thalheimer, W., \& Cook, S. (2002). How to calculate effect sizes from published research articles: A simplified methodology. Retrieved October 20, 2017 from

http://education.gsu.edu/coshima/EPRS8530/Effect_Sizes_pdf 4.pdf

Timur, B., \& Özdemir, M. (2018). Fen eğitiminde artirilmiş gerçeklik ortamlarinin kullanimina ilişkin öğretmen görüşleri [Teachers' views on the use of augmented reality environments in science education]. Uluslararası Türk Eğitim Bilimleri Dergisi, 10, 62-75.

*Tosik Gün, E., \& Atasoy, B. (2017). The effects of augmented reality on elementary school students' spatial ability and academic achievement. Education and Science, 42(191), 31-51.

Turner, H. M. I., \& Bernard, R. M. (2006). Calculating and synthesizing effect sizes. Contemporary Issues in Communication Science and Disorders, 33, 42-55.

Walczak, K., Wojciechowski, R., \& Cellary, W. (2006). Dynamic interactive VR network services for education. In Proceedings of the
ACM Symposium on Virtual reality software and technology (pp. 277-286). ACM.

Wojciechowski, R., \& Cellary, W. (2013). Evaluation of learners' attitude toward learning in ARIES augmented reality environments. Computers \& Education, 68, 570-585.

*Wu, P. H., Hwang, G. J., Yang, M. L., \& Chen, C. H. (2018). Impacts of integrating the repertory grid into an augmented reality-based learning design on students' learning achievements, cognitive load and degree of satisfaction. Interactive Learning Environments, 26(2), 221-234.

*Yen, J. C., Tsai, C. H., \& Wu, M. (2013). Augmented reality in the higher education: Students' science concept learning and academic achievement in astronomy. Procedia - Social and Behavioral Sciences, $103,165-173$.

*Yıldırım, P. (2018). The impact of science teaching made with mobile augmented reality technology on science and technology attitudes and academic achievement of secondary school students (Master's thesis). Firat University, Elaziğ, Turkey.

Yllmaz, R. M. (2016). Educational magic toys developed with augmented reality technology for early childhood education. Computers in Human Behavior, 54, 240-248.

Yung, R. \& Khoo-Lattimore, C. (2019). New realities: a systematic literature review on virtual reality and augmented reality in tourism research. Current Issues in Tourism, 22(17), 2056-2081. 